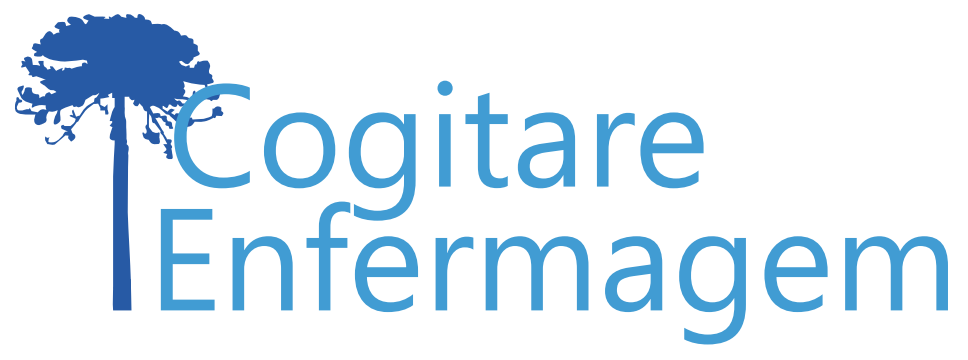

\title{
COMUNICAÇÃO LIVRE
}

\section{PANDEMIA DA COVID-19 E IDOSOS COMO POPULAÇÃO DE RISCO: ASPECTOS PARA EDUCAÇÃO EM SAÚDE}

Polyana Caroline de Lima Bezerra', Luiz Carlos Ribeiro de Lima², Sandro Carvalho Dantas ${ }^{3}$

\section{RESUMO}

Objetivo: discorrer sobre a fisiopatogênese da COVID-19 e vulnerabilidade clínica do indivíduo idoso, além de aspectos relevantes para promoção da saúde e do autocuidado da pessoa idosa. Desenvolvimento: realizou-se investigação dos temas em plataformas científicas de busca, além de documentos oficiais da Organização Mundial de Saúde e do Ministério da Saúde. O vírus causador da COVID-19 apresenta, fundamentalmente, complicações respiratórias. O processo de senescência do aparelho respiratório torna o idoso vulnerável tanto para infecção, como para agravamento e letalidade. Atividade física, nutrição adequada, qualidade do sono, exposição ao sol, saúde mental e espiritualidade permitem a preservação e promoção da saúde dos sistemas imunológicos e respiratórios, e devem ser estimuladas para o autocuidado do idoso.

Conclusão: esta reflexão contribui para orientação de profissionais de saúde no cuidado gerontológico de enfermagem, no procedimento de educação em saúde dos aspectos referentes à prevenção e autocuidado dos idosos, como população de risco para COVID-19.

DESCRITORES: Pandemias; Covid-19; Idoso; Envelhecimento; Enfermagem.

COMO REFERENCIAR ESTE ARTIGO:

Bezerra PC de L, Lima LCR de, Dantas SC. Pandemia da covid-19 e idosos como população de risco: aspectos para educação em saúde. Cogitare enferm. [Internet]. 2020 [acesso em "colocar data de acesso, dia, mês abreviado e ano"]; 25. Disponível em: http://dx.doi.org/10.5380/ce.v25i0.73307. 


\title{
COVID-19 PANDEMIC AND THE ELDERLY AS RISK POPULATION: ASPECTS FOR HEALTH EDUCATION
}

\begin{abstract}
Objective: discuss the physiopathogenesis of COVID-19 and the clinical vulnerability of the elderly person, in addition to relevant aspects for promoting health and self-care for the elderly.

Development: research on the themes was carried out on scientific search platforms, added to official documents from the World Health Organization and the Ministry of Health. The virus that causes COVID-19 basically presents respiratory complications. The senescence process of the respiratory system makes the elderly vulnerable both to infection, as well as to worsening and lethality. Physical activity, adequate nutrition, quality sleep, sun exposure, mental health and spirituality allow the maintenance and promotion of the immune and respiratory systems' health and should be encouraged for the elderly self-care.

Conclusion: this reflection contributes to the guidance of health professionals in gerontological nursing care, in the health education procedure of aspects related to the prevention and selfcare of the elderly, as a population at risk for COVID-19.
\end{abstract}

DESCRIPTORS: Pandemics; Covid-19; Aging; Nursing.

\section{PANDEMIA DE COVID-19 Y ANCIANOS COMO POBLACIÓN DE RIESGO: ASPECTOS PARA EDUCACIONN EN SALUD}

\begin{abstract}
RESUMEN:
Objetivo: Discurrir sobre la fisiopatogénesis del COVID-19 y la vulnerabilidad clínica del anciano, además de aspectos relevantes para promoción de salud y autocuidado del anciano. Desarrollo: Temas investigados en plataformas científicas de búsqueda y en documentos oficiales de la Organización Mundial de la Salud y del Ministerio de Salud. El virus que provoca el COVID-19 presenta, principalmente, complicaciones respiratorias. El proceso de senescencia del aparato respitatorio hace al anciano vulnerable a la infección y a su agravamiento y letalidad. Actividad física, nutrición adecuada, calidad del sueño, exposición al sol, salud mental y espiritualidad permiten la preservación y promoción de salud de los sistemas inmunológicos y respiratorios, y deben estimularse para el autocuidado del anciano. Conclusión: Esta reflexión contibuye a orientar a profesionales de salud en el cuidado gerontológico de enfermería, en educación en salud sobre aspectos referentes a prevención y autocuidado del anciano como población de riesgo de COVID-19.
\end{abstract}

DESCRIPTORES: Pandemias; COVID-19; Anciano, Envejecimiento; Enfermería. 
A COVID-19 é uma doença infecciosa causada pelo vírus Severe Acute Respiratory Syndrome Coronaviru 2 (SARS-CoV-2), convencionalmente chamado de novo coronavírus. Possui período médio de incubação de 5,5 dias e aparecimento de sintomas em até 11 dias em 97,5\% das pessoas infectadas ${ }^{(1)}$. A COVID-19 foi considerada uma pandemia pela Organização Mundial de Saúde (OMS) em 11 de março de 2020(2).

A doença apresenta, fundamentalmente, complicações respiratórias, com $29 \%$ de ocorrência de síndrome de angústia respiratória aguda (SARA). Embora a média de idade dos acometidos seja de 49 anos, a letalidade é maior entre pessoas de 60 anos ou mais ou com doenças pré-existentes ${ }^{(3)}$. Entre os idosos de 60 a 69 anos, a letalidade corresponde a $3,6 \%$, mais elevada que a letalidade da população geral de $2,8 \%$, entre os idosos nos estratos de 70 a 79 anos, a letalidade é de $8 \%$ e entre os de 80 ou mais de $14,8 \%{ }^{(3,4)}$.

No Brasil, até o dia 20 de abril de 2020, foram registrados 2.575 óbitos por COVID-19, representando uma letalidade de $6,3 \%$. Entre os óbitos confirmados, $72,5 \%$ tinham mais de 60 anos e 70\% apresentavam pelo menos uma morbidade. A cardiopatia foi a principal comorbidade associada e esteve presente em $43,2 \%$ dos óbitos da população geral, seguida de diabetes $(33,6 \%)$, pneumopatia $(8,6 \%)$, doença renal $(7,3 \%)$ e doença neurológica $(7,3 \%)$. Em todos os grupos de risco, a maioria dos indivíduos era idoso, exceto para obesidade ${ }^{(5)}$.

Com a verificação da população idosa como componente do grupo de risco para infecção, agravamento e letalidade pelo SARS-CoV-2, a educação em saúde faz-se necessária para efetividade da promoção da saúde direcionada a este nicho populacional. Este artigo tem como objetivo discorrer sobre a fisiopatogênese da COVID-19 e vulnerabilidade clínica do indivíduo idoso, além de aspectos relevantes para a promoção da saúde e do autocuidado da pessoa idosa.

\section{DESENVOLVIMENTO}

Para contemplar o objetivo desta comunicação, utilizou-se referências atualizadas sobre COVID-19, por meio da busca em revistas consagradas na área, como Cell Discovery e The Lancet, além de documentos oficiais da OMS e do Ministério da Saúde. Quanto aos demais aspectos elencados, realizou-se busca pelas plataformas Pubmed e Scielo, utilizando os termos: "aging", "imune system", "exercise", "nutrition", "sleep and health", "mental health".

Foram selecionados os artigos após aplicar filtro da data de publicação (>2012) e estudos com pessoas idosas. Vale a ressalva de que foram incluídas, ainda, outras bibliografias científicas que não se apresentaram nas plataformas investigadas, mas que são consideradas pelos autores como relevantes para a contextualização dos referidos temas.

Com o surgimento de um novo vírus, para o qual a espécie humana ainda não desenvolveu resistência imunológica, o idoso, que apresenta um sistema de defesa corporal menos responsivo comparado à população adulta geral, tem maior dificuldade em responder e combater o novo vírus. Outro fator crítico do coronavírus é o seu tropismo pelo sistema respiratório, que também apresenta diversas alterações com o avanço da idade ${ }^{(6)}$.

\section{O SARS-CoV-2 e vulnerabilidade clínica dos idosos}


OvírusSARS-CoV-2 pertence àsubfamília Coronavirinaedafamília Coronaviridae, eessa subfamília inclui quatro gêneros: Alphacoronavírus, Betacoronavírus, Gammacoronavírus e Deltacoronavírus, sendo o vírus da COVID-19 pertencente aos Betacoronavírus. Seu genoma é uma cadeia simples de ácido ribonucleico (RNA). O SARS-CoV-2 entra pelo mecanismo de chave-fechadura por meio do receptor da ECA2 e a serina protease TMPRSS2 atua como tesoura para quebrar o RNA do vírus e adentrar na célula hospedeira ${ }^{(6)}$.

O receptor ECA2 age como mecanismo contrarregulatório da produção de Angiotensina Il, pela enzima responsável por inativá-la. Nos pulmões, a ECA2 atua nas células epiteliais alveolares I e II, protegendo os pulmões, com ação anti-inflamatória. Lembrando que, além do mecanismo hipertensivo de vasoconstrição, a ligação da Angiotensina II aos receptores AT2R1 está associada à ativação de células do sistema imune e produção de citocinas inflamatórias. No entanto, o SARS-CoV-2, ao utilizar o receptor ECA2 para entrar na célula, causa expressão diminuída destes receptores, seja por ocupar seu sítio de ligação, seja pela destruição da célula invadida ${ }^{(7)}$.

A consequência deste processo é a ativação exacerbada da Angiotensina II, devido à falta do mecanismo contrarregulador da ECA2. A expressão da ECA2 nas células pulmonares verifica-se nos alvéolos tipo II, que correspondem apenas a $5 \%$ das células alveolares, mas possuem duas funções essenciais: 1 . nas células alveolares de surfactantes e 2. nos precursores dos alvéolos tipo I, responsáveis por $95 \%$ das células alveolares. Portanto, a célula-alvo atacada pelo SARS-CoV-2 está envolvida na reserva de células regenerativas e produção de surfactantes, eventos essenciais para o reparo do dano alveolar sofrido(8).

Estas constatações poderiam, então, explicar o espectro clínico tão variado da doença, e suas diferenças entre jovens e idosos. Em adultos saudáveis, tem-se o maior número de receptores ECA2, associado à maior capacidade de regeneração e resposta imune mais eficiente, apresentando poucos ou nenhum sintoma. Por outro lado, os idosos possuem menor expressão de ECA2 ou a presença de comorbidades, como hipertensão e cardiopatias, que interferem no sistema da angiotensina, ou diabetes, que prejudica o sistema imune. Nestes indivíduos, a maior carga viral e o dano sustentado das células que expressam ECA2 levam à perda da capacidade regenerativa, causando inflamação pulmonar e grande risco de desenvolvimento de SARA, devido à resposta inflamatória descontrolada ${ }^{(7,9)}$.

Além disso, o processo de senescência do aparelho respiratório torna os indivíduos idosos mais vulneráveis às complicações respiratórias pelo SARS-CoV-2, a citar: a diminuição do número de macrófagos pulmonares, que resulta na menor capacidade de enfrentamento da infecção respiratória; a diminuição da elasticidade dos tecidos, dos alvéolos, dos lobos pulmonares inferiores e diminuição do número de capilares, o que repercute em um acúmulo de secreções nos pulmões e diminuição das trocas gasosas; alterações musculoesqueléticas da caixa torácica (tórax de barril), tornando-a mais resistente, diminuindo a capacidade de respirar profundamente e de tossir, reação importante para eliminar o excesso de secreção nas vias respiratórias ${ }^{(8)}$.

Nos próximos tópicos, elencaram-se os aspectos moduladores do sistema imunológico e que auxiliam o aparelho respiratório, assim como as atitudes de preservação e promoção da saúde dos idosos que podem ser abordadas pelos profissionais de saúde no procedimento de educação em saúde.

\section{Prática de atividade física}

O envelhecimento é acompanhado por alterações no sistema imunológico, processo conhecido como imunossenescência. Esse estado é caracterizado por alterações no tamanho das células T, padrão de secreção de citocinas, capacidade celular e produção de anticorpos, que culminam em um estado pró-inflamatório e uma capacidade diminuída de responder a novos antígenos ${ }^{(10)}$. Além das interações com patógenos, o microbioma e a nutrição do hospedeiro, o exercício e o estresse, e muitos outros fatores externos, são moduladores cruciais desse processo de imunossenescência(11). 
A prática de exercícios físicos está associada à eficiência do sistema imunológico, por meio do aumento da capacidade proliferativa de células T, elevação da função neutrófila e atividade citotóxica das células Natural Killer (NK), viabilizando a função de destruir células tumorais ou infectadas por vírus e de diminuição do estresse. Reforça-se a importância do incentivo à prática regular de exercícios nos idosos, uma vez que minimiza efeitos que a idade avançada induz no sistema imunológico, como a diminuição da resposta proliferativa das células imunológicas ${ }^{(11,12)}$.

A OMS recomenda para os idosos a prática de atividade física diária por 75 minutos por semana com exercícios aeróbicos de intensidade vigorosa ou 150 minutos por semana de intensidade moderada, com fortalecimento muscular duas vezes por semana ${ }^{(13)}$.

\section{Nutrição}

A tríade de inflamação, estresse oxidativo e envelhecimento das células imunes representa importantes mecanismos que podem ser melhorados por meio da nutrição adequada(14,15). A microbiota intestinal pode ter um impacto na deterioração relacionada ao envelhecimento por sua atividade nutricional e imunomoduladora ${ }^{(16)}$. O processo de envelhecimento leva a alterações da microbiota intestinal e modificações na resposta imune, que podem estar associadas ao aumento do risco de doenças ${ }^{(17)}$.

O consumo inadequado de alimentos como refrigerantes e açúcares pode influenciar o desenvolvimento de doenças metabólicas e o envelhecimento celular acelerado(18). A obesidade pode ser um fator que contribui para a carga cumulativa de estresse oxidativo, inflamação crônica ao longo da vida e, portanto, contribui para o encurtamento acelerado dos telốmeros ${ }^{(19)}$.

Portanto, a oferta de micro e macronutrientes e alimentos antioxidantes é essencial para a boa resposta imunológica e aporte energético necessário ao funcionamento do corpo do idoso ${ }^{(20)}$. Micronutrientes são as vitaminas e minerais essenciais para o funcionamento do corpo. As vitaminas $A, E, C$ e $D$ e os minerais ferro, zinco, selênio e magnésio são moduladores do fortalecimento do sistema imunológico e são encontrados em alimentos como peixes, ostras, ovos, espinafre, couve, beterraba, cereais integrais, feijões e frutas oleaginosas (nozes, castanhas e amêndoas), carnes em geral, aves e frutos do mar, castanhas do Brasil e de caju, entre outros ${ }^{(21)}$. Macronutrientes são as substâncias básicas para a nutrição do organismo e correspondem aos carboidratos, proteínas e gorduras. A deficiência de proteína na dieta prejudica a função imunológica. Os aminoácidos têm papel importante na regulação das células de defesa do organismo. Para garantir o consumo proteico, é importante consumir carne, frango, peixe, ovos, leite e derivados, feijão, leguminosas, castanhas e oleaginosas. Alimentos antioxidantes como frutas cítricas e frutas vermelhas, e compostos bioativos (probióticos, como iogurtes, bebidas lácteas fermentadas, kefir e kombuchá) agem na prevenção de doenças e na proteção do sistema imunológico ${ }^{(22)}$.

Com o avançar da idade, a água corporal total diminui, devido à redução do líquido entre as células, aumentando o risco de desidratação e complicações do trato respiratório. É imprescindível a reposição adequada de líquidos ${ }^{(8)}$.

\section{Qualidade do sono}

A privação do sono diminui a produção de células de defesa e o metabolismo de radicais livres, ou seja, afeta a imunidade e aumenta os processos inflamatórios. A privação de sono está quase sempre relacionada aos eventos estressores, que acarretam um aumento da atividade do sistema nervoso simpático que, em resposta, libera demasiadamente glicocorticoide que exerce ação imunossupressora no organismo humano. Não obstante, estudos atuais associam a insônia crônica às alterações imunológicas, pela redução de células CD3, CD4 e CD8 ${ }^{(23)}$.

Pessoas em privação de sono são 4,5 vezes mais propensas a desenvolver gripes e 
resfriados comparadas às que dormem no mínimo 8 horas por noite ${ }^{(24)}$. Segundo a National Sleep Foundation, a duração de sono recomendada em 24 horas para os idosos é de 7 a 8 horas ${ }^{(25)}$. Todavia, com o processo de senescência, ocorre a diminuição da produção do hormônio melatonina, cujas funções influenciam o ritmo circadiano, interferindo tanto na qualidade quanto na quantidade de sono. As principais queixas dos idosos em relação ao sono são: aumento de despertares após o início do sono, necessidade de cochilos durante o dia, sono fragmentado e mudanças na amplitude do ritmo circadiano ${ }^{(26)}$.

Contudo, apesar dessas queixas serem frequentes, tais alterações não devem ser banalizadas. A equipe multiprofissional de saúde precisa estar atenta para intervir quando necessário, seja no tratamento medicamentoso ou não, ou ainda na prevenção. Neste último, manter hábitos saudáveis como atividade física, alimentação adequada e práticas de higiene do sono são importantes aliados na manutenção da qualidade sono(27).

\section{Exposição ao sol}

A exposição ao sol, além de auxiliar na qualidade do sono pelo ciclo sono-vigília, ativa a produção de vitamina $D$, considerada um antídoto para depressão, importante no aumento da vitalidade e melhora do sistema imunológico. A atividade imunorreguladora da vitamina $D$ pode ser compreendida a partir de suas funções no sistema imunológico, pela regulação da diferenciação e ativação de linfócitos CD4; aumento do número e função das células T reguladoras; diminuição da produção das interferon-g, IL-2 e TNF-a, a partir de células Th1 e estímulo da função células Th17, contribuindo para o aumento da imunidade inata do organismo. Recomenda-se que os idosos fiquem expostos à luz solar de 15 a 20 minutos por dia, preferencialmente antes das 10 horas e após as 16 horas ${ }^{(28)}$.

\section{Saúde mental e espiritualidade}

Cada vez mais, a ciência evidencia a importância da espiritualidade no bem estar geral dos indivíduos, pelo aumento de biomarcadores essenciais para a modulação do estresse e reações inflamatórias. O estresse, por sua vez, pode ser prejudicial ao organismo a partir de uma resposta imunossupressora relativa à liberação excessiva de hormônios estressores pró-inflamatórios. A descoberta da comunicação bidirecional entre os sistemas neuroendócrino, neurológico e o sistema imunológico, denominada de psiconeuroimunologia, permitiu criar relações entre os estressores físicos, psicossociais e a resposta imune ${ }^{(29)}$.

Neste contexto, atividades simples no cotidiano, como a prática de meditação, dança, caminhadas, reza/oração, jardinagem, pintura, prática da gratidão, conexão com animais de estimação, dedicação nos projetos de vida entre outras, auxiliam na condução de problemas e gerenciamento de crises. Estas práticas, somadas ao fortalecimento social com amigos e familiares, mesmo que virtualmente, contribuem para um envelhecer saudável com base em vida satisfatória e esperançosa ${ }^{(30)}$.

\section{CONSIDERAÇÕES FINAIS}

Os idosos compõem a população de risco para COVID-19 e os aspectos relacionados a esta vulnerabilidade foram abordados nesta comunicação, visando incentivar os profissionais de saúde a utilizar estas informações no procedimento de educação em saúde para os idosos e seus comunicantes.

Esta reflexão contribui para a orientação de profissionais de saúde, especialmente da atenção primária à saúde e no cuidado gerontológico de enfermagem, referente à prevenção, promoção da saúde e autocuidado dos idosos, como população de risco para COVID-19. 
1. Lauer SA, Grantz KH, Bi Q, Jones FK, Zheng Q, Meredith HR, et al. The incubation period of Coronavirus disease 2019 (COVID-19) from publicly reported confirmed cases: estimation and application. Ann Intern Med. [Internet]. 2020 [acesso em 02 abr 2020]. Disponível em: https://doi.org/10.7326/M200504.

2. World Health Organization (WHO). Rolling updates on coronavirus disease (COVID-19). [Internet]. Geneva: WHO; 2020 [acesso em 20 abr 2020]; Disponível em: https://www.who.int/emergencies/diseases/ novel-coronavirus-2019/events-as-they-happen.

3. Huang C, Wang Y, Li X, Ren L, Zhao J, Hu Y, et al. Clinical features of patients infected with 2019 novel coronavirus in Wuhan, China. Lancet. [Internet]. 2020 [acesso em 26 abr 2020]; 395(10223). Disponível em: https://doi.org/10.1016/S0140-6736(20)30183-5.

4. Chinese Center for Disease Control and Prevention. The Epidemiological Characteristics of an Outbreak of 2019 Novel Coronavirus Diseases (COVID-19) - China. 2020. CCDC Weekly. [Internet]. 2020 [acesso em 27 abr 2020]; 2. Disponível em: https://static.poder360.com.br/2020/02/CDC-Coronavirusfebruary.pdf.

5. Ministério da Saúde (BR). Centro de Operações de Emergência em Saúde Pública. Boletim Epidemiológico COE COVID-19, n. 13. Situação Epidemiológica: doença pelo Coronavírus 2019. [Internet]. 2020 [acesso em 25 abr 2020]; Disponível em: https://portalarquivos.saude.gov.br/images/ pdf/2020/April/21/BE13---Boletim-do-COE.pdf.

6. Chen Y, Liu Q, Guo D. Emerging coronaviruses: genome structure, replication, and pathogenesis. J Med Virol. [Internet]. 2020 [acesso em 26 abr 2020]; 92(4). Disponível em: https://doi.org/10.1002/ jmv.25681.

7. Rivellese F, Prediletto E. ACE2 at the centre of COVID-19 from paucisymptomatic infections to severe pneumonia. Autoimmun Rev. [Internet]. 2020 [acesso em 26 abr 2020]; 19(6). Disponível em: https://doi. org/10.1016/j.autrev.2020.102536.

8. Wold GH. Enfermagem Gerontológica. 5. ed. Rio de Janeiro: Elsevier; 2012. Alterações fisológicas. p.40-44.

9. Hoffmann M, Kleine-Weber H, Schroeder S, Müller MA, Drosten C, Pöhlmann S, et al. SARS-CoV-2 cell entry depends on ACE2 and TMPRSS2 and Is blocked by a clinically proven protease inhibitor. Cell. [Internet]. 2020 [acesso em 26 abr 2020]; 181(2). Disponível em: https://doi.org/10.1016/j. cell.2020.02.052.

10. Araújo AL de, Silva LCR, Fernandes JR, Benard G. Preventing or reversing immunosenescence: can exercise be an immunotherapy? Immunotherapy [Internet]. 2013 [acesso em 27 abr 2020]; 5(8). Disponível em: https://doi.org/10.2217/imt.13.77.

11. Müller L, Pawelec G. Aging and immunity - impact of behavioral intervention. Brain Behav Immun [Internet]. 2014 [acesso em 27 abr 2020]; 39. Disponível em: https://doi.org/10.1016/j.bbi.2013.11.015.

12. Sellami M, Gasmi M, Denham J, Hayes LD, Stratton D, Padulo J, et al. Effects of acute and chronic exercise on immunological parameters in the elderly aged: can physical activity counteract the effects of aging? Front Immunol [Internet]. 2018 [acesso em 27 abr 2020]; 9(2187). Disponível em: https://doi. org/10.3389/fimmu.2018.02187.

13. Hammami A, Harrabi B, Mohr M, Krustrup P. Physical activity and coronavirus disease 2019 (COVID-19): specific recommendations for home-based physical training. Manag Sport Leis [Internet]. 2020 [acesso em 26 abr 2020]; Disponível em: https://doi.org/10.1080/23750472.2020.1757494.

14. Pfrimer K, Ferriolli E, Takeuchi PL, Salles MSV, Saran-Netto A, Zanetti MA, et al. Effects of the consumption of milk biofortified with selenium, vitamin $E$, and different fatty acid profile on immune 
response in the elderly. Mol Nutr Food Res [Internet]. 2018 [acesso em 27 abr 2020]; 62(4). Disponível em: https://doi.org/10.1002/mnfr.201700307.

15. Kiecolt-Glaser JK, Epel ES, Belury MA, Andridge R, Lin J, Glaser R, et al. Omega-3 fatty acids, oxidative stress, and leukocyte telomere length: a randomized controlled trial. Brain Behav Immun [Internet]. 2013 [acesso em 27 abr 2020]; 28. Disponível em: https://www.ncbi.n/m.nih.gov/pmc/articles/ PMC3545053/.

16. Landete JM, Gaya P, Rodríguez E, Langa S, Peirotén A, Medina M, et al. Probiotic bacteria for healthier aging: immunomodulation and metabolism of phytoestrogens. Biomed Res Int [Internet]. 2017 [acesso em 27 abr 2020]; 2017(5939818). Disponível em: https://www.ncbi.nlm.nih.gov/pmc/articles/ PMC5646295/.

17. Liu Y, Gibson GR, Walton GE. An in vitro approach to study effects of prebiotics and probiotics on the faecal microbiota and selected Immune parameters relevant to the elderly. PLoS One [Internet]. 2016 [acesso em 27 abr 2020]; 11(9). Disponível em: https://www.ncbi.nlm.nih.gov/pmc/articles/PMC5017648/.

18. Leung CW, Laraia BA, Needham BL, Rehkopf DH, Adler NE, Lin J, et al. Soda and cell aging: associations between sugar-sweetened beverage consumption and leukocyte telomere length in healthy adults from the National Health and Nutrition Examination Surveys. Am J Public Health [Internet]. 2014 [acesso em 27 abr 2020]; 104(12). Disponível em: https://www.ncbi.nlm.nih.gov/pmc/articles/ PMC4229419/.

19. Gielen M, Hageman GJ, Antoniou EE, Nordfjall K, Mangino M, Balasubramanyam M, et al. Body mass index is negatively associated with telomere length: a collaborative cross-sectional meta-analysis of 87 observational studies. Am J Clin Nutr [Internet]. 2018 [acesso em 27 abr 2020]; 108(3). Disponível em: https://www.ncbi.nlm.nih.gov/pmc/articles/PMC6454526/.

20. Sarni ROS, Souza FIS, Cocco RR, Mallozi MC, Solé D. Micronutrientes e sistema imunológico. Rev bras alerg imunopatol [Internet]. 2010 [acesso em 10 jun 2020]; 33(1). Disponível em: http://www.sbai.org.br/ revistas/Vol331/ART\%201-10\%20-\%20Micronutrientes\%20e\%20sistema\%20imunol\%C3\%B3gico.pdf.

21. Rosa VD, Galgani M, Santopaolo M, Colamatteo A, Laccetti R, Matarese G. Nutritional control of immunity: balancing the metabolic requirements with an appropriate immune function. Semin Immunol. [Internet]. 2015 [acesso em 26 abr 2020]; 27(5). Disponível em: https://doi.org/10.1016/j. smim.2015.10.001.

22. Sociedade Brasileira de Diabetes. Recomendações nutricionais e COVID-19. [Internet]. 2020 [acesso em 11 jun 2020]; Disponível em https://www.diabetes.org.br/covid-19/recomendacoes-nutricionais-ecovid-19/.

23. Palma BD, Tiba PA, Machado RB, Tufik S, Suchecki D. Repercussões imunológicas dos distúrbios do sono: o eixo hipotálamo-pituitária-adrenal como fator modulador. Rev. Bras. Psiquiatr. [Internet]. 2007 [acesso em 26 abr 2020]; 29( suppl1). Disponível em: https://doi.org/10.1590/S1516-44462007000500007.

24. Prather AA, Janicki-Deverts $D$, Hall MH, Cohen S. Behaviorally assessed sleep and susceptibility to the common cold. Sleep. [Internet]. 2015 [acesso em 26 abr 2020]; 38(9). Disponível em: https://doi. org/10.5665/sleep.4968.

25. Hirshkowitz M, Whiton K, Albert SM, Alessi C, Bruni O, DonCarlos L, et al. National Sleep Foundation's sleep time duration recommendations: methodology and results summary. Sleep Health. [Internet]. 2015 [acesso em 26 abr 2020]; 1(1). Disponível em: https://doi.org/10.1016/j.sleh.2014.12.010.

26. Bringhurst FR, Demay MB, Kronenberg HM. Hormones and disorders of mineral metabolism. In: Kronenberg HM, Melmed S, Polonsky KS, Larsen PR editors. Williams Textbook of Endocrinology. 11. ed. Philadelphia: Elsevier; 2008.

27. Marques CDL, Dantas AT, Fragoso TS, Duarte ALBP. A importância dos níveis de vitamina D nas doenças autoimunes. Rev. Bras. Reumatol. [Internet]. 2010 [acesso em 24 abr 2020]; 50(1). Disponível em: https://doi.org/10.1590/S0482-50042010000100007. 
28. Marques-Deak A, Sternberg E. Psiconeuroimunologia: a relação entre o sistema nervoso central e o sistema imunológico. Rev. Bras. Psiquiatr. [Internet]. 2004 [acesso em 24 abr 2020]; 26(3). Disponível em: https://doi.org/10.1590/S1516-44462004000300002.

29. Melo RLP de, Eulálio M do C, Gouveia WV, Silva HDM. O efeito do estresse na qualidade de vida de idosos: o papel moderador do sentido de vida. Psicol Reflex. Crit. [Internet]. 2013 [acesso em 26 abr 2020]; 26(2). Disponível em: https://doi.org/10.1590/S0102-79722013000200002.

30. Blackburn E, Epel, E. O segredo está nos telômeros: receita revolucionária para manter a juventude e viver mais e melhor. São Paulo: Planeta; 2017.

Recebido: $29 / 04 / 2020$

Finalizado: 18/08/2020

Editora associada: Luciana Puchalski Kalinke

Autor Correspondente:

Polyana Caroline de Lima Bezerra

Universidade Federal do Acre

Rd. BR 364, Km 04 - 69920-900 - Rio Branco, AC, Brasil

E-mail: polyana@ufac.br

Contribuição dos autores:

Contribuições substanciais para a concepção ou desenho do estudo; ou a aquisição, análise ou interpretação de dados do estudo - PCLB

Elaboração e revisão crítica do conteúdo intelectual do estudo - PCLB, LCRL, SCD

Aprovação da versão final do estudo a ser publicado - PCLB, LCRL, SCD

Responsável por todos os aspectos do estudo, assegurando as questões de precisão ou integridade de qualquer parte do estudo - PCLB 